\title{
Erratum
}

\section{Histological and genetic evidence for a variant of superficial spreading melanoma composed predominantly of large nests}

Heinz Kutzner, Gisela Metzler, Zsolt Argenyi, Luis Requena, Gabriele Palmedo, Thomas Mentzel, Arno Rütten, Markus Hantschke, Bruno E Paredes, Leo Schärer, Benedikt Hesse, Leila El Shabrawi-Caelen, Isabella Fried, Helmut Kerl, Lorenzo Cerroni, Rajmohan Murali and Thomas Wiesner

Modern Pathology (2012) 25, 1178; doi:10.1038/modpathol.2012.67

Correction to: Modern Pathology (2012) 25, 838-845; doi:10.1038/modpathol.2012.35; published online 2 March 2012
In this article, the name of the twelfth author is incorrect; the correct name is Laila El-ShabrawiCaelen. 